UNIVERSIDADE DE SÃO PAULO

ESCOLA POLITÉCNICA

\title{
INVESTIGAÇÕES SOBRE O ACABAMENTO SUPERFICIAL DE USINAGENS COM ALTÍSSIMA VELOCIDADE DE CORTE
}

\author{
Autor: Ian Faccio
}

Dissertação apresentada à Escola Politécnica da Universidade de São Paulo, para concorrer ao Título de Mestre, pelo curso de Pós-Graduação em Engenharia Mecânica - Área de concentração: Projeto e Fabricação.

Orientador: Prof. Dr. Marco Stipkovic F ${ }^{\mathbf{0}}$ 
Data da Defesa:

1

\section{Banca Examinadora}

Prof. Dr.

Julgamento:

Assinatura:

Prof. Dr.

Julgamento:

Assinatura:

Prof. Dr.

Julgamento:

Assinatura:

Prof. Dr.

Julgamento:

Assinatura:

Prof. Dr.

Julgamento:

Assinatura: 
À minha família, fonte inesgotável de motivação e perseverança. 


\section{AGRADECIMENTOS}

Aos amigos e orientadores Prof. Dr. Gilmar Ferreira Batalha e Prof. Dr. Marco Stipkovic Filho, pelo constante apoio e diretrizes essenciais.

Ao Prof. Dieter Bousseljot e ao Instituto Tecnológico BrasilAlemanha pelo equipamento e instalações utilizados.

A todos que direta ou indiretamente, colaboraram na execução deste trabalho. 


\section{SUMÁRIO}

p.

RESUMO

SUMMARY / ABSTRACT

1 INTRODUÇÃ

1.1 Apresentação.....................................................................

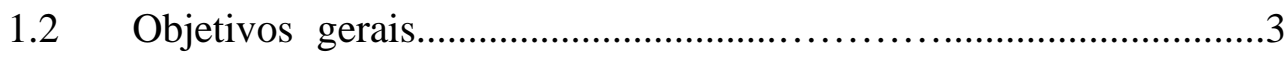

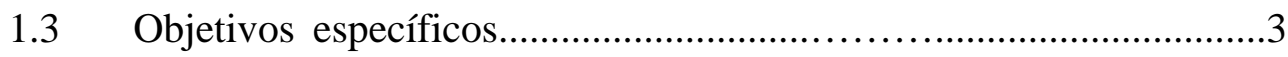

2 REVISÃO DA LITERATURA

USINAGEM COM ALTÍSSIMA VELOCIDADE DE CORTE.......5

2.1 Aspecto Histórico........................................................................

2.2 Definição de Usinagem com Altíssima Velocidade de Corte............10

2.3 Processos de Usinagem com Altíssima Velocidade de Corte...........14

2.4 Materiais e Métodos de Ensaio com Altíssima Velocidade de Corte........................................................25

2.5 Máquinas para Altíssima Velocidade de Corte.........................38

2.6 Processos de Formação de Cavaco com Altíssima Velocidade de Corte...................................................49

2.7 Ferramentas para Altíssima Velocidade de Corte......................59

3 REVISÃO DA LITERATURA

RUGOSIDADE ............................................72

3.1 Conceito de Rugosidade....................................................... 72 
3.2 Aplicações de Parâmetros de Rugosidade..............................76

3.3 Definições de Alguns Parâmetros de Rugosidade........................79

4 PROCEDIMENTO EXPERIMENTAL ...................................86

4.1 Apresentação..................................................................86

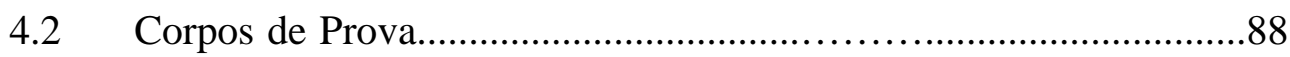

4.3 Valores Analisados e Equipamento Utilizado.............................90

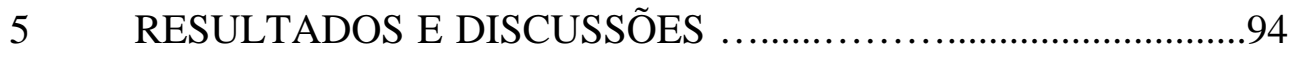

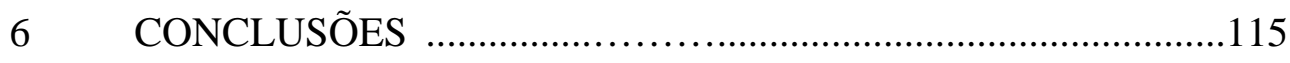

REFERÊNCIAS BIBLIOGRÁFICAS..............................................119 


\section{LISTA DE FIGURAS}

Figura 1 - Princípio de Salomon.................................................................6

Figura 2 - Tempos de operações de usinagem............................................8

Figura 3 - Campo de aplicação da velocidade de corte ...............................10

Figura 4 - Classificação das máquinas fresadoras....................................12

Figura 5 - Classificação do tipo de rebarbas..............................16

Figura 6 - Comparação das velocidades de avanço..................................... 20

Figura 7 - Contraste da distribuiçãa de esforços..........................................22

Figura 8 - Mecanismo do processo de amortecimento...................28

Figura 9 - Diagrama de estabilidade .................................29

Figura 10 - Diagrama esquemático de medição de temperaturas locais......35

Figura 11 - Seqüência de usinagem....................................36

Figura 12 - Conjunto de aplicações otimizadas..........................39

Figura 13 - Diagrama de tipos de peças diferentes......................40

Figura 14 - Diagrama de alguns materiais de engenharia..................44

Figura 15 - Utilização de um eixo para evitar interferências...............48

Figura 16 - Metodologia para determinação..............................51

Figura 17 - Primeira fase da formação de um cavaco......................53

Figura 18 - Segunda fase da formação de um cavaco.....................53

Figura 19 - Terceira fase da formação de um cavaco.....................54 
Figura 20 - Quarta fase da formação de um cavaco.......................54

Figura 21 - Analogia entre espessura da transferência seletiva............57

Figura 22 - Deformações no acoplamento............................63

Figura 23 - Corte esquemático do sistema de acionamento................64

Figura 24 - Exemplo de desempenho em relação ao desgaste..............68

Figura 25 - Exemplo de representação de um perfil de rugosidade..........73

Figura 26 - Ilustração do parâmetro de rugosidade $\mathrm{R}_{\mathrm{a}} \ldots \ldots \ldots \ldots \ldots \ldots \ldots \ldots . . \ldots 79$

Figura 27 - Ilustração do parâmetro de rugosidade $\mathrm{R}_{\mathrm{y}} \ldots \ldots \ldots \ldots \ldots \ldots \ldots \ldots . \ldots . \ldots . \ldots$

Figura 28 - Ilustração do parâmetro de rugosidade $\mathrm{R}_{\mathrm{z}} \ldots \ldots \ldots \ldots \ldots \ldots \ldots \ldots \ldots 1$

Figura 29 - Comparação de duas distribuições de alturas de perfis.........84

Figura 30 - Arranjo da fixação dos corpos de prova......................89

Figura 31 - Resultados de Rugosidade média $\left(\mathrm{R}_{\mathrm{a}}\right) \ldots \ldots \ldots \ldots \ldots \ldots \ldots \ldots \ldots . \ldots . \ldots . \ldots 5$

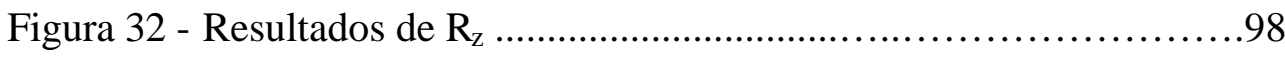

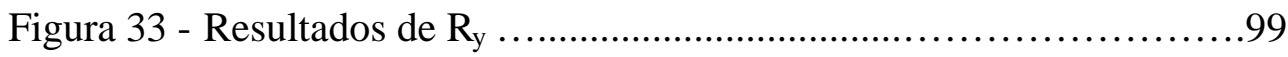

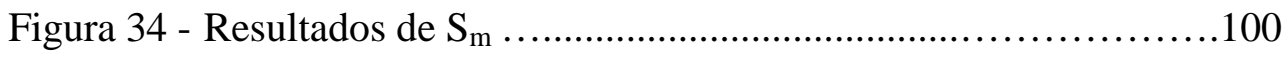

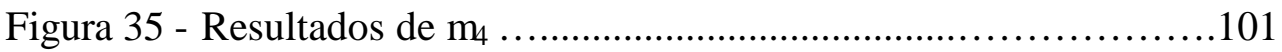

Figura 36 - Exemplo da estrutura metalográfica do $1^{\mathrm{o}}$ corpo de prova......103

Figura 37 - Exemplo da estrutura metalográfica do $2^{\underline{0}}$ corpo de prova......104

Figura 38 - Exemplo da estrutura metalográfica do $3^{\circ}$ corpo de prova.......105 


\section{LISTA DE TABELAS}

TABELA 1 - Comparação entre os processo de usinagem..........................18

TABELA 2 - Características construtivas dependentes do material.......44

TABELA 3 - Exemplo comparativo dos aspectos construtivos............45

TABELA 4 - Modelos de excitação para vibrações ......................67

TABELA 5 - Valores de $\mathrm{R}_{\mathrm{a}}$ atingíveis..............................76

TABELA 6 - Configuração da profundidade de corte conforme o ensaio...87

TABELA 7 - Configuração da distribuição dos ensaios ...................88

TABELA 8 - Desempennho de processos de retificação e torneamento....108

TABELA 9 - Desempennho de processos de torneamento e fresamento...109

TABELA 10 - Comparação entre os processo de usinagem........................111 


\section{LISTA DE ABREVIATURAS E SIGLAS}

CAD - Projeto auxiliado por computador

CAM - Manufatura auxiliada por computador

CAPP - Planejamento de processos auxiliado por computador

Cermet - material composto de mistura de cerâmicas com metais

CBN - Nitreto Cúbico de Boro

CNC - Comando numérico computadorizado

CVD - Deposição química de vapor

DIN - Norma técnica alemã

HB - Dureza Brinell

HSCO - Aço rápido com Cobalto

HSK - Mandril normalizado alemão de fuso oco

HSM - Usinagem com altíssima velocidade de corte

HVM - Usinagem de alta velocidade

ISO - Norma técnica internacional (Organização para normalização internacional)

LSM - Usinagem de baixa velocidade

MD - Metal duro

MQL - Quantidade mínima de lubrificação

NURBS - Splines tipo B Racionais Não-Uniformes

PFC - Polímero Reforçado com Fibras de Carbono

PVD - Deposição física de vapor 
UHSM - Usinagem de velocidade ultra alta

VB - Maior dimensão do desgaste na aresta da pastilha de corte

VDI - Norma da indústria automobilística alemã

VHSM - Usinagem de velocidade muito alta 


\section{LISTA DE SÍMBOLOS}

a - avanço, mm.min ${ }^{-1}$

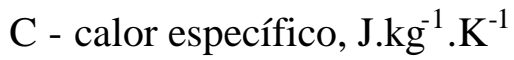

D - quantidade de picos em um perfil de rugosidade

e - excentricidade residual permissível, $\mu \mathrm{m}$

F - força, N

f - freqüência de rotação operacional, $\mathrm{Hz}$

h - espaçamento da malha de elementos finitos

J - equivalente mecânico do calor, J

$\mathrm{K}_{1}$ - fator de adaptação

$\mathrm{k}$ - condutibilidade térmica, $\mathrm{kg} \cdot \mathrm{m} \cdot \mathrm{s}^{-3} \cdot \mathrm{K}^{-1}$

$1_{m}$ - comprimento medido da rugosidade, $\mathrm{mm}$

m - massa, $\mathrm{kg}$

$\mathrm{m}^{*}$ - massa combinada da ferramenta e do eixo do fuso, $\mathrm{kg}$

q - geração de calor, J

V - velocidade de corte

$\mathrm{V}_{\mathrm{CAV}}$ - velocidade do cavaco, $\mathrm{m} \cdot \mathrm{min}^{-1}$

$\mathrm{V}_{\mathrm{CIS}}$ - velocidade no plano de cisalhamento, $\mathrm{m} \cdot \mathrm{min}^{-1}$

$\mathrm{V}_{\mathrm{c}}$ - velocidade de corte, $\mathrm{m} \cdot \mathrm{min}^{-1}$

$\mathrm{V}_{\mathrm{MAX}}$ - velocidade vibracional máxima 
$\mathrm{T}$ - temperatura, ${ }^{\circ} \mathrm{C}, \mathrm{K}$

$\mathrm{T}_{\mathrm{CIS}}$ - temperatura no plano de cisalhamento, $\mathrm{K}$

$\mathrm{T}_{\mathrm{INT}}$ - temperatura na interface cavaco-ferramenta, $\mathrm{K}$

$\mathrm{t}$ - tempo, s

$\gamma$ - ângulo de folga da ferramenta, ${ }^{o}$

$\varepsilon$ - deformação

$\varepsilon_{\mathrm{R}}$ - deformação referencial

$\kappa$ - difusividade do calor

$\mu$ - coeficiente de atrito

$\rho$ - densidade, $\mathrm{kg} \cdot \mathrm{m}^{-3}$

$\sigma$ - tensão de escoamento, $\mathrm{MPa}$

$\theta$ - espessura do filme fluido, $\mu \mathrm{m}$

$\tau_{\mathrm{PLA}}$ - tensão de cisalhamento no plano primário de cisalhamento, $\mathrm{MPa}$

$\tau_{\mathrm{FER}}$ - tensão de cisalhamento na face da ferramenta, MPa

$\phi$ - diâmetro, mm

$\Omega$ - freqüência de excitação, $\mathrm{s}^{-1}$

$\omega$ - freqüência natural, $\mathrm{s}^{-1}$ 


\section{RESUMO}

FACCIO, I. Investigações sobre o acabamento superficial de usinagens com altíssima velocidade de corte. 2002, 126p. Dissertação Mestrado - Escola Politécnica, Universidade de São Paulo, São Paulo.

Corpos de prova de ferro fundido foram usinados com altíssima velocidade de corte. Tiveram diversos parâmetros de sua rugosidade medida e os valores foram descritos em gráficos de rugosidade versus profundidade de corte. Pode-se verificar uma dependência entre estes valores, mas não o clássico aumento da rugosidade conforme o aumento da profundidade de corte. Realizou-se ainda a inspeção metalográfica dos corpos de prova na busca de mudanças de fase na estrutura ferro carbono que indiquem temperaturas elevadas no local, causadas pela alta velocidade de corte.

Palavra-chave: Usinagem, Altíssima Velocidade de Corte, Rugosidade, Processos de Fabricação. 


\section{SUMMARY / ABSTRACT}

FACCIO, I. Investigations on the quality of high-speed machined surfaces. 2002, 126p. Dissertação Mestrado - Escola Politécnica, Universidade de São Paulo, São Paulo.

Cast iron test parts were high-speed machined. They had several roughness parameters measured and these values were plotted on roughness versus depth of cut charts. It could be noticed a relation between these values, but not the classical roughness increase due to the increase of depth of cut. Moreover, the metalographical analisys was performed for these test parts, in a search for phase changes on the carbon-iron structure which indicate high temperatures at the region, caused by the high cutting speed.

Keywords: $\quad$ Machining, HSM, Roughness, Manufacturing Processes. 


\section{AUTORIZAÇÃo}

Autorizo a reprodução e/ou divulgação total ou parcial da presente obra, por qualquer meio convencional ou eletrônico, desde que citada a fonte.

Ian Faccio

Assinatura do autor:

Instituição: Escola Politécnica da USP

Local: São Paulo

Endereço: Av. Escola Politécnica

E-mail: $\underline{\text { ian.faccio@poli.usp.br }}$ 